\title{
sciendo
}

\section{TREATMENT OF HEPATOCELLULAR CARCINOMAS BY HEPATIC TRANSARTERIAL CHEMOEMBOLIZATION, CASE PRESENTATION AND REVIEW OF THE LITERATURE}

\author{
ANDREI FLORIN BLOJ ${ }^{1}$, IOANA HĂLMACIU ${ }^{2}$, BOGDAN ANDREI SUCIU ${ }^{3}$, \\ LUCIAN MĂRGINEAN ${ }^{4}$ \\ 1,2,4 Tîrgu Mureș County Emergency Clinical Hospital,
2,3 "George Emil Palade" University of Medicine, Pharmacy, Science and Technology, Tîrgu Mureş
}

Keywords: hepatocellular carcinoma, hepatic transarterial chemoembolization
Abstract: Hepatocellular carcinoma is one of the most common liver tumours. At the time of diagnosis, only $20 \%$ of patients are suitable for liver resection for curative purposes. In patients who are not suitable for surgical resection, chemoembolization of the hepatic artery is a viable therapeutic option. We present the case of a 60-year-old male patient being admitted with a diagnosis of liver tumour in the right liver lobe. Abdominal angio-CT examination revealed the existence of a tumour formation of $9 \times 10 \mathrm{~cm}$ in the liver segments IV, VIII. Given the large size of the tumour, as well as the patient's comorbidities, it was decided to practice hepatic chemoembolization with Irinotecan. The clinical evolution was favourable, the patient being discharged 48 hours after the intervention. Hepatic transarterial chemoembolization is a viable alternative in the treatment of patients with unresectable hepatocellular carcinomas, which may improve the prognosis of these patients.

\section{INTRODUCTION}

Among primary liver tumours, the most common histological type is hepatocellular carcinoma, which accounts for about $90 \%$ of most liver tumours.(1) The main therapeutic techniques with curative objective in these cases are represented by the surgical resection, respectively the liver transplant. Unfortunately, $75 \%$ of patients with hepatocellular carcinomas seek medical attention in advanced stages of the disease, which does not allow a curative treatment in these cases. $(2,3)$

In the past, the only therapeutic chance for patients with unresectable hepatocellular carcinomas was systemic chemotherapy and radiotherapy. In the last 10 years, due to the development of new interventional imaging techniques, there has been an increase in the importance of chemo-embolization of the hepatic artery (TACE), with its variant chemoembolization with drug-eluting beads (DEB-TACE).(4) Also, lately, in such cases, ablative techniques using radiofrequency or alcoholization, performed under percutaneous ultrasound guidance, are used more frequently. $(5,6)$

\section{AIM}

The purpose of this paper is to present the case of a patient with unresectable hepatocellular carcinoma where hepatic artery chemoembolization was performed and to conduct a literature review in this regard.

\section{CASE REPORT}

We present the case of a 60 -year-old male patient admitted at the Surgery Clinic of the Tîrgu Mureș County Emergency Clinical Hospital. At admittance, the patient presented asthenia, fatigue, weight loss, pain in the right hypochondrium. As for the laboratory findings, they were within normal parameters. The abdominal angio-CT examination showed the existence of a tumour formation in the right hepatic lobe, in segments IV, VIII with a diameter of $9 \times 10 \mathrm{~cm}$ (figures no.1,2).

Figure no. 1. Abdominal angio-CT examination, coronary section showing a space occupying lesion of 9x10 cm diameter with inhomogeneous iodophilia located in segments IV, VIII

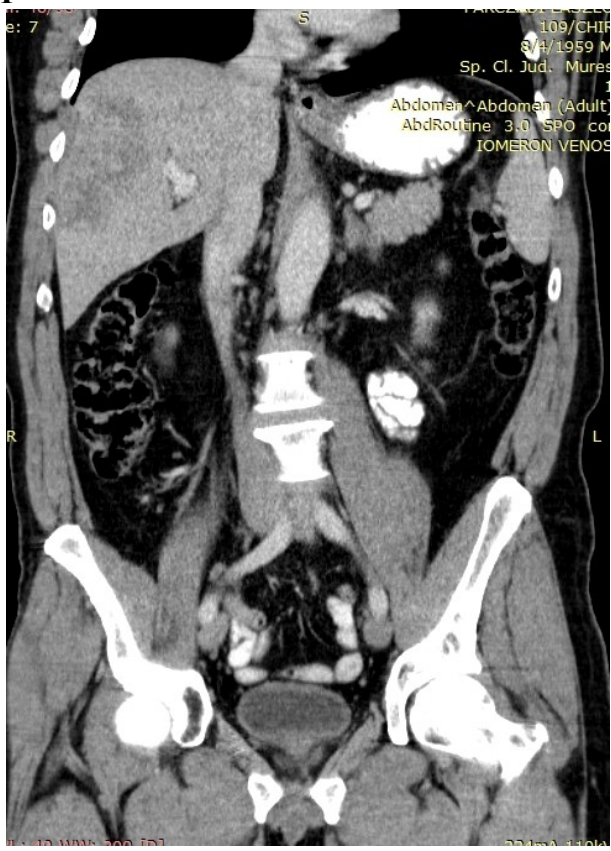

${ }^{2}$ Corresponding author: Ioana Hălmaciu, Str. Ghe. Marinescu, Nr. 50, Târgu-Mureș, România, E-mail: anca halmaciu@yahoo.com, Phone: +407400 91324

Article received on 09.06.2020 and accepted for publication on 10.08.2020 


\section{CLINICAL ASPECTS}

Figure no. 2. Abdominal angio-CT examination, axial section that highlights a space occupying lesion of 9x10 cm diameter with inhomogeneous iodophilia located in segments IV, VIII

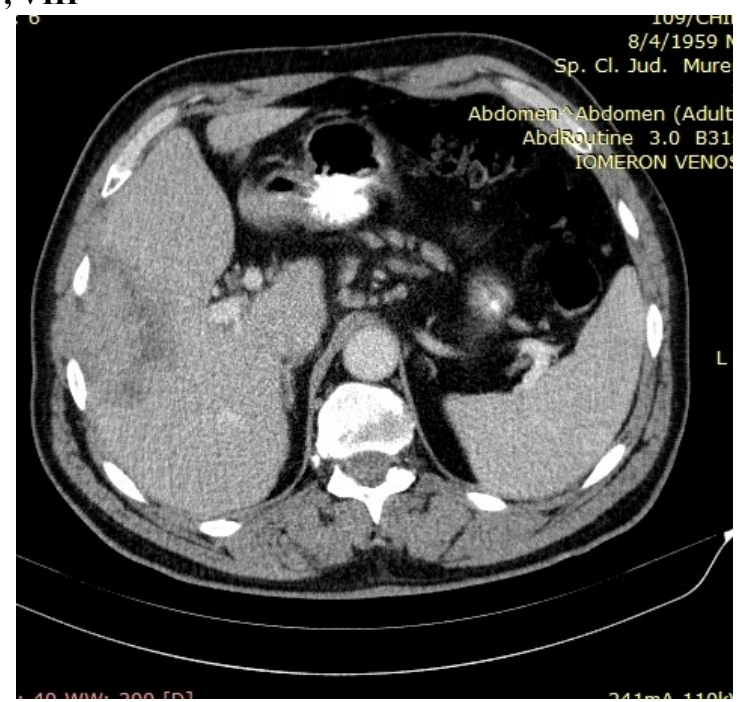

Given the large size of the tumour and the increased operative risk due to the associated cardiac comorbidities, it was decided to delay the surgical intervention in exchange for a chemoembolization of the hepatic artery. The intervention was performed under local anesthesia, practicing chemoembolization of arterial branches tributary to the tumour formation with embolization particles of Irinotecan (figure no. 3). The clinical evolution after the intervention was favourable, the patient presented in the first 24 hours a transient increase in serum values of transaminases that returned to normal after the introduction of hepatoprotective treatment.

Figure no. 3. Chemoembolization of hepatic artery with Irinotecan (angiographic aspect)

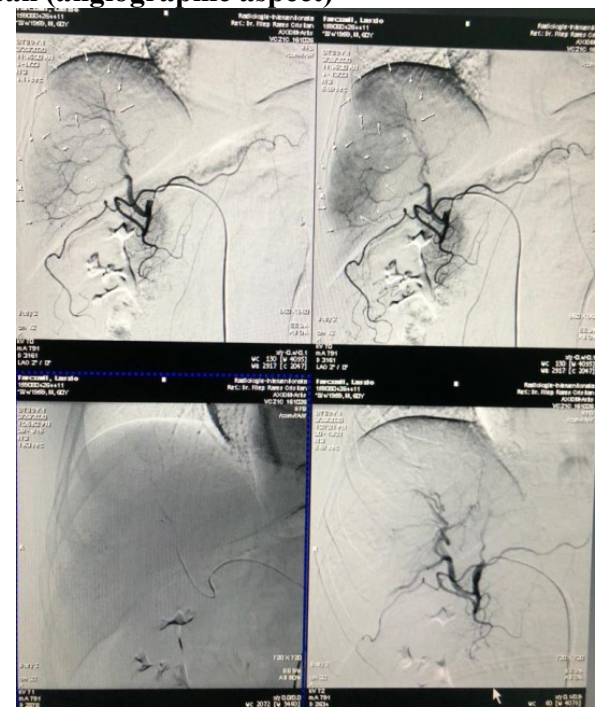

\section{DISCUSSIONS}

At the time of diagnosis, only about $20 \%$ of patients with hepatocellular carcinomas are suitable for curative treatment. This particularly low rate is due on the one hand to the tumour itself which is not suitable for curative resection, on the other hand due to the underlying condition of the patient's liver parenchyma (cirrhotic liver, alcoholic liver, chronic hepatitis $\mathrm{C}$ virus infection or B).(7-9)

Intra-arterial treatment for patients with hepatocellular carcinoma is increasingly used. The motivation for practicing such therapeutic approach is based on the observation that the tumoral tissue is vascularised mainly by the hepatic artery, instead, the normal liver tissue has mainly a portal vascularization. Currently, both TACE and selective internal radiation therapy (SIRT) are used in clinical practice. $(10,11)$ TACE is usually recommended in patients with multifocal tumours, without vascular invasion, without distant metastases, who have an acceptable clinical status and liver function within relatively normal parameters. SIRT, unlike TACE, is performed in patients with vascular invasion or after TACE failure.(12-14) SIRT is in fact a variant of loco-regional brachytherapy. Currently, there is no clear information in the literature to suggest the superiority of one of the two therapeutic approaches in terms of prognosis of these patients. Often, the option for one of the two therapeutic methods is based mainly on the experience of the medical centre where the therapeutic intervention is practiced. The main limiting factor of these therapeutic approaches is the obtaining of an incomplete tumour necrosis following these loco-regional therapies.(12)

Given that most patients with hepatocellular carcinomas seek medical attention in advanced stages of the disease when they are no longer suitable for surgical treatment, the practice of loco-regional therapies in such patients accompanied by a much lower morbidity is of real use. The application of loco-regional chemotherapy has the advantage that the introduction of chemotherapy in the hepatic artery increases its effectiveness on the liver tumour with the existence of lower systemic side effects. Also, during the practice of TACE, due to the embolization of the arterial branches tributary to the tumour, the contact time of the chemotherapeutic drug with the tumour cells increases. Usually, during TACE, chemotherapy is given in combination with lipiodol. Another advantage is represented by the fact that this technique can be performed under local anesthesia, it is not necessary to perform a general anesthesia. This aspect is of particular importance in clinical practice, because the vast majority of these patients have numerous comorbidities, the risks of general anesthesia in such cases being much higher.(15,16) Also, the ischemic effect produced on the tumour due to the occlusion of arterial sources that vascularise the tumour causes a partial necrosis of the tumour formation.(17)

In order to improve the prognosis of patients undergoing TACE, some authors recommend the association of embolization with microspheres. This method determines a superior efficacy in terms of decreasing the vascular flow at the level of the tumour formation. The cytotoxic effect of the chemotherapeutic agent in association with tumour tissue ischemia will ultimately lead to inhibition of the tumour growth. $(18,19)$ At the level of the hepatic parenchyma, following the hypoxia, there is an increased cellular expression of vascular endothelial growth factor (VEGF). $(20,21)$ This hyperexpression at the cellular level of VEGF will determine in time the appearance of neoformation vessels, proliferation of endothelial cells, as well as inhibition of apoptosis at the cellular level. These cellular processes resulting from increased cell secretion may ultimately lead to growth of the tumour formation, representing one of the main causes that may limit the clinical effects of TACE.(22-24)

In the case of SIRT, the use of Y90 microspheres does not cause a permanent occlusion of the arterial branches that are embolized, therefore hypoxia and tissue inflammatory response is smaller.(25) Unlike TACE, DEB-TACE uses nonbiodegradable polymer microspheres, which results in irreversible vascular occlusion of the embolized vessel. This causes a much higher tissue concentration of the administered chemotherapy agent associated with a longer period of contact 


\section{CLINICAL ASPECTS}

between it and the tumour tissue whilst maintaining a very low systemic concentration, which determines a much higher tolerability of the method for the patient.(26.27)

The main complications that can occur after practicing TACE are nausea, vomiting, fever, abdominal pain or local complications at the site of the arterial puncture. $(28,29)$ In the literature, the so-called post-embolization syndrome is currently recognized, being characterized by the appearance of fever and a transient increase in serum transaminases in the first 72 hours after the practice of TACE. The pathogenesis of this syndrome relies in the appearance of tumour necrosis, as well as hypoxia, respectively ischemia of the healthy liver tissue. $(30,31)$ Although the vast majority of patients have mild forms of this syndrome, there are a couple of cases mentioned in the literature where patients even developed liver failure. The occurrence of this syndrome varies in the literature between $45-80 \%$ of cases, its frequency depending on the experience of the medical staff where the intervention is practiced.(32-34)

Some authors have observed that the occurrence and the severity of post-embolization syndrome is not associated with a favourable therapeutic response, but is associated with a poor long-term prognosis and a higher long-term mortality of these patients. $(35,36)$ Often, the occurrence of postembolization syndrome in such patients is associated with increased serum levels of IL-6; being known in the literature the importance of IL-6 in regeneration, respectively hepatic homeostasis. In this regard, some authors consider that the increase in serum IL-6 levels is in fact a marker of the onset of post-embolization liver regeneration processes. $(37,38)$

In the treatment of post-embolization syndrome, the vast majority of authors recommend the administration of $\mathrm{N}$ acetylcysteine due to its hepatoprotective and antioxidant role.(39)

In the long term, the survival of patients with unresectable hepatocellular carcinomas where TACE is practiced in combination with systemic chemotherapy varies between $26-47 \%$ at 3 years, these results varying depending on the experience of the centre where the procedure is performed. The outcome of TACE in these patients is particularly important, given that the 3-year survival rate in patients undergoing only systemic chemotherapy is around 3\%. These results support the importance of the use of TACE in the therapeutic arsenal of patients with unresectable hepatocellular carcinomas.(40-43) On the other hand, regarding the prognosis of patients undergoing TACE and DEB-TACE there are contradictions in the literature on this subject. Some studies show a superiority of long-term survival after practicing DEBTACE, but most studies show no differences in long-term survival between the two methods.(44)

\section{CONCLUSIONS}

Hepatic transarterial chemoembolization is a viable alternative in the treatment of patients with unresectable hepatocellular carcinomas, which may improve the prognosis of these patients.

REFERENCES

1. Katsanos K, Kitrou P, Spiliopoulos S, Maroulis I, Petsas T, Karnabatidis D., Comparative effectiveness of different transarterial embolization therapies alone or in combination with local ablative or adjuvant systemic treatments for unresectable hepatocellular carcinoma: A network metaanalysis of randomized controlled trialsPLoS One. 2017 Sep 21;12(9):e0184597. doi 10.1371/journal.pone.0184597

2. Bruix J, Sherman M, Practice Guidelines Committee AAftSoLD. Management of hepatocellular carcinoma.
Hepatology. 2005;42(5):1208-36. pmid:16250051.

3. Bruix J, Reig M, Sherman M. Evidence-Based Diagnosis, Staging, and Treatment of Patients with Hepatocellular Carcinoma. Gastroenterology. 2016;150(4):835-53 pmid:26795574.

4. Ray CE Jr., Brown AC, Green TJ, Winston H, Curran C, Kreidler SM, et al. Survival outcomes in patients with advanced hepatocellular carcinoma treated with drugeluting bead chemoembolization. AJR American journal of roentgenology. 2015;204(2):440-7. pmid:25615768.

5. Fu Y, Zhao X, Yun Q, Zhu X, Zhu Y, Li Q, et al. Transarterial chemoembolization (TACE) plus percutaneous ethanol injection (PEI) for the treatment of unresectable hepatocellular carcinoma: a meta-analysis of randomized controlled trials. International journal of clinical and experimental medicine. 2015;8(7):10388-400 pmid:26379829.

6. Facciorusso A, Di Maso M, Muscatiello N. Microwave ablation versus radiofrequency ablation for the treatment of hepatocellular carcinoma: A systematic review and metaanalysis. International journal of hyperthermia: the official journal of European Society for Hyperthermic Oncology, North American Hyperthermia Group. 2016:1-6. pmid:26794414

7. Ni JY, Xu LF, Wang WD, Sun HL, Chen YT., Conventional Transarterial Chemoembolization vs Microsphere Embolization in Hepatocellular Carcinoma: A Meta-Analysis, World J Gastroenterol. 2014 Dec 7;20(45):17206-17. doi: 10.3748/wjg.v20.i45.17206.

8. Page AJ, Cosgrove DC, Philosophe B, Pawlik TM. Hepatocellular carcinoma: diagnosis, management, and prognosis. Surg Oncol Clin N Am. 2014;23:289-311.

9. Kennedy AS, Sangro B. Nonsurgical treatment for localized hepatocellular carcinoma. Curr Oncol Rep. 2014; 16:373

10. Aubé C, Bouvier A, Lebigot J, Vervueren L, Cartier V, Oberti F. Radiological treatment of HCC: interventional radiology at the heart of management, Diagn Interv Imaging. 2015;96:625-636.

11. Galle PR, Forner A, Llovet JM, Mazzaferro V, Piscaglia F, Raoul JL, et al. EASL Clinical Practice Guidelines: management of hepatocellular carcinoma, J Hepatol. 2018;69:182-236.

12. Delicque J, Hermida M, Piron L, Allimant C, Belgour A, Pageaux GP, Ben Bouallegue F, Assenat E, MarianoGoulart D, Guiu B, Cassinotto C. Intra Arterial Treatment of Hepatocellular Carcinoma: Comparison of MELD Score Variations Between Radio-Embolization and ChemoEmbolization, Diagn Interv Imaging. 2019 Nov;100(11):689-697. doi: 10.1016/j.diii.2019.05.006.

13. Vogel A, Cervantes A, Chau I, Daniele B, Llovet JM, Meyer T, et al. Hepatocellular carcinoma: ESMO Clinical practice guidelines for diagnosis, treatment and follow-up, Ann Oncol. 2019;30:871-873.

14. de Lope CR, Tremosini S, Forner A, Reig M, Bruix J. Management of HCC, J Hepatol. 2012;56:75-87.

15. Llovet JM, Zucman-Rossi J, Pikarsky E, Sangro B, Schwartz M, Sherman M, et al. Hepatocellular carcinoma. Nature reviews Disease primers. 2016;2:16018. pmid:27158749.

16. Lencioni R, de Baere $\mathrm{T}$, Soulen MC, Rilling WS, Geschwind JH. Lipiodol transarterial chemoembolization for hepatocellular carcinoma: A systematic review of efficacy and safety data. Hepatology. 2016. pmid:26765068

17. Facciorusso A, Di Maso M, Muscatiello N. Drug-eluting beads versus conventional chemoembolization for the 


\section{CLINICAL ASPECTS}

treatment of unresectable hepatocellular carcinoma: A meta-analysis. Digestive and liver disease: official journa of the Italian Society of Gastroenterology and the Italian Association for the Study of the Liver. 2016. pmid:26965785.

18. Breunig IM, Shaya FT, Hanna N, Seal B, Chirikov VV, Daniel Mullins C. Transarterial chemoembolization treatment: association between multiple treatments, cumulative expenditures, and survival. Value Health 2013;16:760-768.

19. Leelawat K, Laisupasin P, Kiatdilokrut A, Pongtongpool T, Narong S, Samkhumphim N, Ket-Horm S. The effect of doxorubicin on the changes of serum vascular endothelial growth factor (VEGF) in patients with hepatocellular carcinoma after transcatheter arterial chemoembolization (TACE). J Med Assoc Thai. 2008;91:1539-1543.

20. Chen C, Wang J, Liu R, Qian S. RNA interference of hypoxia-inducible factor-1 alpha improves the effects of transcatheter arterial embolization in rat liver tumors. Tumour Biol. 2012;33:1095-1103.

21. Jia ZZ, Jiang GM, Feng YL. Serum HIF-1alpha and VEGF levels pre- and post-TACE in patients with primary liver cancer. Chin Med Sci J. 2011;26:158-162.

22. Winiarski BK, Wolanska KI, Rai S, Ahmed T, Acheson N, Gutowski NJ, Whatmore JL. Epithelial ovarian cancerinduced angiogenic phenotype of human omental microvascular endothelial cells may occur independently of VEGF signaling. Transl Oncol. 2013;6:703-714.

23. Li J, Xu Y, Long XD, Wang W, Jiao HK, Mei Z, Yin QQ, Ma LN, Zhou AW, Wang LS. Cbx 4 governs HIF-1 $\alpha$ to potentiate angiogenesis of hepatocellular carcinoma by its SUMO E3 ligase activity. Cancer Cell. 2014;25:118-131.

24. Srabovic N, Mujagic Z, Mujanovic-Mustedanagic J, Softic A, Muminovic Z, Rifatbegovic A, Begic L. Vascular endothelial growth factor receptor-1 expression in breast cancer and its correlation to vascular endothelial growth factor a. Int J Breast Cancer. 2013;2013:746749.

25. Sato K, Lewandowski RJ, Bui JT, Omary R, Hunter RD, Kulik L, Mulcahy M, Liu D, Chrisman H, Resnick S. Treatment of unresectable primary and metastatic liver cancer with yttrium-90 microspheres (TheraSphere): assessment of hepatic arterial embolization. Cardiovasc Intervent Radiol. 2006;29:522-529.

26. Song MJ, Chun HJ, Song do S, Kim HY, Yoo SH, Park $\mathrm{CH}$, Bae SH, Choi JY, Chang UI, Yang JM. Comparative study between doxorubicin-eluting beads and conventional transarterial chemoembolization for treatment of hepatocellular carcinoma. J Hepatol. 2012;57:1244-1250.

27. van Malenstein $H$, Maleux G, Vandecaveye V, Heye S, Laleman W, van Pelt J, Vaninbroukx J, Nevens F, Verslype C. A randomized phase II study of drug-eluting beads versus transarterial chemoembolization for unresectable hepatocellular carcinoma. Onkologie. 2011;34:368-376.

28. Salem R, Lewandowski RJ, Mulcahy MF, Riaz A, Ryu RK, Ibrahim S, Atassi B, Baker T, Gates V, Miller FH. Radioembolization for hepatocellular carcinoma using Yttrium-90 microspheres: a comprehensive report of longterm outcomes. Gastroenterology. 2010;138:52-64.

29. Hawkins CM, Kukreja K, Geller JI, Schatzman C, Ristagno R. Radioembolisation for treatment of pediatric hepatocellular carcinoma. Pediatr Radiol. 2013;43:876-881

30. Chan AO, Yuen MF, Hui CK, Tso WK, Lai CL. A prospective study regarding the complications of transcatheter intraarterial lipiodol chemoembolization in patients with hepatocellular carcinoma. Cancer. 2002;94:1747-1752.

31. Siramolpiwat S, Punjachaipornpon $\mathrm{T}$, Pornthisarn $\mathrm{B}$,
Vilaichone RK, Chonprasertsuk S, Tangaroonsanti A, Bhanthumkomol P, Phumyen A, Yasiri A, Kaewmanee M., N-Acetylcysteine Prevents Post-embolization Syndrome in Patients with Hepatocellular Carcinoma Following Transarterial Chemoembolization, Dig Dis Sci. 2019 Nov;64(11):3337-3345. doi: 10.1007/s10620-019-05652-0

32. Tasneem AA, Abbas Z, Luck NH, Hassan SM, Faiq SM. Adverse events following transarterial chemoembolization for hepatocellular carcinoma and factors predicting such events. J Pak Med Assoc. 2013;63:239-244.

33. Chan AO, Yuen MF, Hui CK, Tso WK, Lai CL. A prospective study regarding the complications of transcatheter intraarterial lipiodol chemoembolization in patients with hepatocellular carcinoma. Cancer. 2002;94:1747-1752.

34. Leung DA, Goin JE, Sickles C, Raskay BJ, Soulen MC. Determinants of postembolization syndrome after hepatic chemoembolization. J Vasc Interv Radiol. 2001;12:321326.

35. Jun $\mathrm{CH}, \mathrm{Ki} \mathrm{HS}$, Lee HK, et al. Clinical significance and risk factors of postembolization fever in patients with hepatocellular carcinoma. World J Gastroenterol. 2013;19:284-289.

36. Mason MC, Massarweh NN, Salami A, Sultenfuss MA, Anaya DA. Post-embolization syndrome as an early predictor of overall survival after transarterial chemoembolization for hepatocellular carcinoma. HPB (Oxford). 2015;17:1137-1144.

37. Schmidt-Arras D, Rose-John S. IL-6 pathway in the liver: from physiopathology to therapy. J Hepatol. 2016;64:14031415.

38. Yamaguchi K, Itoh Y, Yokomizo C, et al. Blockade of IL-6 signaling exacerbates liver injury and suppresses antiapoptotic gene expression in methionine cholinedeficient diet-fed db/db mice. Lab Invest. 2011;91:609-618

39. Lauterburg BH, Corcoran GB, Mitchell JR. Mechanism of action of $\mathrm{N}$-acetylcysteine in the protection against the hepatotoxicity of acetaminophen in rats in vivo. J Clin Invest. 1983;71:980-991.

40. Camma C, Schepis F, Orlando A et al. (2002) Transarterial chemoembolization for unresectable hepatocellular carcinoma: meta-analysis of randomized controlled trials. Radiology 224:47-54.

41. Llovet JM, Bruix J. Systematic review of randomized trials for unresectable hepatocellular carcinoma: chemoembolization improves survival. Hepatology. 2003;37:429-442.

42. Marelli L, Stigliano R, Triantos C et al. (2007) Transarterial therapy for hepatocellular carcinoma: which technique is more effective? A systematic review of cohort and randomized studies. Cardiovasc Intervent Radiol. 2007;30:6-25.

43. Mason MC, Massarweh NN, Salami A, Sultenfuss MA, Anaya DA., Post-embolization syndrome as an early predictor of overall survival after transarterial chemoembolization for hepatocellular carcinoma, HPB (Oxford). 2015 Dec;17(12):1137-44. doi: 10.1111/hpb.12487.

Li H, Wu F, Duan M, Zhang G., Drug-eluting bead transarterial chemoembolization (TACE) vs conventional TACE in treating hepatocellular carcinoma patients with multiple conventional TACE treatments history. A comparison of efficacy and safety. Medicine (Baltimore). 2019 May;98(21):e15314. doi: 10.1097/MD.0000000000015314. 